\title{
Treatment of Morbid Obesity
}

\section{Shahid Habib ${ }^{1 *}$, Julia Samamé ${ }^{2}$ and Carlos A Galvani}

${ }^{1}$ Division of Gastroenterology and Hepatology, Department of Medicine and Division of Transplantation, Department of Surgery, University of Arizona, USA ${ }^{2}$ Section of Minimally Invasive \& Robotic Surgery, Department of Surgery College of Medicine, University of Arizona, USA

\begin{abstract}
Prevalence of obesity is increasing and approaching a pandemic. It is largely driven by changes in living environment and behavior as a result of technological modernization. These factors change our diets and lifestyles and promote a state of positive energy balance. Weight loss is the key treatment in patients with obesity and related complications, and it cannot be achieved without having a positive change in behavior and lifestyle. Bariatric surgery is effective treatment with long-term results for the treatment of morbid obesity, resolution of comorbidities, and improved life expectancy. This comprehensive review includes new insights and concepts in lifestyle interventions and bariatric surgery for the treatment of morbid obesity.
\end{abstract}

Keywords: Morbid obesity; Bariatric surgery; Weight loss; Treatment

\section{Introduction}

\section{Obesity: A global health problem}

In past decades, dietary changes to ward high-carbohydrate foods (mainly sugars), in conjunction with reductions in physical activity due to modern, technology-driven lifestyles, have resulted in an epidemic of obesity and its related complications [1-3]. In the United States, Behavioral Risk Factor Surveillance System (BRFSS) data showed a prevalence of obesity of $26 \%$ compared to National Health and Nutrition Examination Survey (NHANES) prevalence of 35.7\% [4,5].

Extensive data have been published revealing deteriorating quality of life and psychosocial functioning as a result of a wide spectrum of complications [6-8]. In a meta-analysis, Body Mass Index (BMI) categories were associated with higher all-cause and cause-specific mortality; hazard ratios (HR) 0.94 for overweight and 1.18 for obesity all grades combined [9]. In the US, adults with a BMI greater than $40 \mathrm{~kg} / \mathrm{m}^{2}$ had a higher risk of death from cancer than normal-weight subjects [10]. In 2008, US medical costs equal to US\$ 147 billion per year were attributed to obesity and to provision of care of patients with type II diabetes mellitus and related sequelae [11,12]. Similar results were reported from other countries [13].

Weight loss is the key treatment in patients with obesity and related complications. This obesity epidemic warrants prevention strategies in order to have a measurable effect on the population. These strategies should include high-level policies and coordinated efforts by governments, organizations, communities and individuals to positively influence behavioral change in society. Treatment of obesity includes Lifestyle Intervention (LI), pharmacotherapy, and bariatric surgery. Benefits of weight loss on mortality, general well-being, and other related complications have been well-documented $[8,14-18]$.

\section{Medical treatment}

Medical treatment of obesity is the first step in the management of obesity. It starts with recognizing obesity as a disease and initiating behavioral therapy for LI, which is the backbone of weight loss treatment and includes lifelong changes in diet, eating patterns, and activity level. Pharmacotherapy and bariatric surgery can be added if LI remains insufficient. Bariatric surgery, in conjunction with lifestyle intervention, is effective treatment of morbid obesity [19-21].

\section{Lifestyle intervention}

A key concept to losing weight with or without surgery: Reversal of positive energy balance to a negative state is the key concept to weight loss $[22,23]$. Failure to achieve or maintain a negative energy balance results in failure of treatment. Negative energy balance is defined as greater Total Daily Energy Expenditure (TDEE) than energy intake (energy expenditure $>$ energy intake).

\section{Weight Loss $=$ TDEE $>$ energy intake}

A negative energy balance of $500 \mathrm{kcal} /$ day is required to lose a pound of weight over one week (daily required calorie intake $=$ [energy expenditure-500]), which is a reasonable and safe rate. Faster weight loss at a rate greater than 3 pounds $(1.5 \mathrm{~kg})$ per week is not safe and is not recommended. A minimum weight loss of $5-7 \%$ is required to achieve some improvement in health parameters, and the risks of obesity decline to baseline by achieving ideal BMI [22].

The major energy components of TDEE are Basal Energy Expenditure (BEE), Diet-Induced Thermogenesis (DIT), and ActivityInduced Energy Expenditure (AEE) [24].

\section{TDEE $=\mathrm{BEE}+\mathrm{DIT}+\mathrm{AEE}$ (exercise and non-exercise)}

$\mathrm{BEE}$ is the largest component of TDEE (60-75\%). It is defined as the energy utilized by the body in resting state to maintain vital functions for the body to sustain life. There are several factors that affect BEE. $B E E$ varies among individuals based upon inherent metabolic rate and three-quarters of the variability in BEE is predicted by lean body mass; additionally, BEE declines with aging. Deregulation of TOR signaling alters whole body metabolism and causes age-related changes [25]. DIT, the second component of TDEE, is the energy expenditure associated with the digestion, absorption, and storage of food and it accounts for approximately $10-15 \%$ of TDEE [26]. AEE is the most variable of all components of TDEE [27]. Its two sub components are Exercise-induced Energy Expenditure (EEE) and Non-Exercise Physical Activity (NEPA). NEPA includes the energy expenditure of all occupation, leisure, sitting, standing, and ambulation [27]. Due to the normal variations in non-exercise activity and the aforementioned variations in BEE among people, total daily energy expenditure varies

*Corresponding author: Shahid Habib, College of Medicine, University of Arizona 1501 N. Campbell Avenue, Tucson, AZ, USA, Tel: (520) 626-5952; Fax: (520) 6265975; E-mail: shabib@surgery.arizona.edu

Received March 18, 2013; Accepted June 15, 2013; Published June 25, 2013

Citation: Habib S, Samamé J, Galvani CA (2013) Treatment of Morbid Obesity. Surgery Curr Res 3: 135. doi:10.4172/2161-1076.1000135

Copyright: () 2013 Habib S, et al. This is an open-access article distributed under the terms of the Creative Commons Attribution License, which permits unrestricted use, distribution, and reproduction in any medium, provided the original author and source are credited. 
greatly in humans. The coefficients of variation in these components of TDEE are around $5-8 \%$ for BEE, $1-2 \%$ for EEE, and about $20 \%$ for DIT.

Formulae to calculate BEE and total daily energy expenditures (TDEE) are as below (Harris-Benedict Equation):

- For men,

$\mathbf{B E E}=66.5+(13.75 \mathrm{x} \mathrm{kg})+(5.003 \mathrm{x} \mathrm{cm})-(6.775 \mathrm{x}$ age $)$

- For women,

$\mathbf{B E E}=655.1+(9.563 \mathrm{x} \mathrm{kg})+(1.850 \times \mathrm{cm})-(4.676 \mathrm{x}$ age $)$

- Total Daily Energy Expenditure (TDEE):

TDEE=BEE $\times$ PAI $(1.2-2.5)$

- Physical Activity Index (PAI):

\section{$\mathbf{P A I}=\mathrm{TDEE} / \mathrm{BEE}$}

Setting the goals of lifestyle intervention: Sustainable weight loss is the primary goal of a comprehensive weight management program. An important objective during weight loss is to maximize fat loss while minimizing the loss of metabolically active Fat-Free Mass (FFM). Massive weight loss typically results in substantial loss of FFM, potentially slowing metabolic rate [26]. Aiming to lose $10 \%$ of baseline body weight is a realistic goal and is associated with reduced morbidity and increased quality of life and survival. Continued adherence to dietary restrictions, healthy diet, and improved activity is the key to success of additional modalities of weight loss.

Factors affecting lifestyle intervention: Lifestyle intervention can result in long-lasting weight loss [27]. Attrition rates of greater than fifty percent have been reported. In a multidisciplinary weight management clinic, higher attrition rates were noted among medically (54\%) than surgically (11\%) treated patients. Multivariate analyses identified participation in the medical clinic, younger patient age, and lower body mass index as predictors of attrition [28].

Noncompliance and deficit in decision-making: Long-term adherence to LI recommendations is vital. Poor adherence to lifestyle is the most common limiting factor to sustained weight loss and its beneficial effects. A $34 \%$ dropout rate and suboptimal adherence to dietary regimen have been reported [29]. Deficit in decision-making may be a factor in failure to adhere to weight loss recommendations. The prefrontal cortex (PFC) of the brain has been identified as playing a crucial role in several aspects of behavior including eating, physical activity, decision-making (particularly regarding risks and benefits), moral cognition, self-recognition, and body image. The PFC is more important under conflicting situations when inappropriate responses need to be inhibited [30]. Obesity has also been a marker of relapse and low treatment adherence in many epidemiologic studies [31].

Comprehensive education: It is the mainstay of LI. Published literature support the importance of comprehensive nutrition education for achieving more effective weight reduction [32]. Its effectiveness has also been reported after bariatric surgery [33]. Pre-operative participation in a medically supervised weight management program appears to have a positive effect on physical activity postoperatively; however, it did not show any benefit on degree of weight loss [34].

Behavioral therapy: It is associated with modest benefit in achieving and maintaining weight loss [35]. Financial incentive has shown benefit in losing and maintaining weight [36]. Psychological intervention is essential for some vulnerable patients before and during the difficult process of LI as well as before and after bariatric surgery
[37]. One study did not find a positive effect from Short Message Service Maintenance Treatment (SMSMT) on weight, eating behavior, or psychological well-being [38]. In a RCT behavior therapy did not improve weight loss [39].

Monitoring: Continued monitoring of total daily energy intake, eating patterns and physical activity is mandated to achieve and maintain effective weight loss. Several calorie counters are available online, but simple and effective tools to monitor LI are still lacking. Pedometers are simple devices which are effective to monitor daily physical activity (AEE). A simple device designed to monitor waist circumference in obese individuals could be used to help maintain their health conditions. This devised system is composed of calorie tracking and a waist circumference module [40]. Its efficacy has yet to be validated.

Supervised weight loss: In the US, many health insurance payers mandate that bariatric surgery candidates undergo a Medically Supervised Weight Management (MSWM) program prior to approving the surgery. However, MSWM did not provide additional benefit as compared to the standard preoperative bariatric surgery protocol in terms of weight loss and most behavioral outcomes after Lap-Band Adjustable Gastric Binding (LAGB ${ }^{\circ}$ [34].

Complex recommendations: Adherence becomes an issue because of the complexity of recommendations, inadequate counseling, and socioeconomic reasons [28].

Slowing of metabolic rate: Another factor that plays a role in regaining of weight is slowing of metabolic rate despite the relative preservation of fat-free mass after weight loss. Resting metabolism slowed dramatically and out of proportion to weight loss, despite exercise. This metabolic adaptation may persist during weight maintenance and predispose patients to weight regain unless high levels of physical activity or caloric restriction are maintained [26].

\section{Dietary Regimen for Weight Loss}

There are two components of dietary interventions: a) balanced calorie restriction and b) modified dietary composition. In the modified dietary composition approach, the main goal is change in macronutrient composition, which could be achieved with or without defined calorie restriction. Multiple dietary approaches for weight loss have been studied using either approach alone or in combination with other interventions. Overall, all dietary approaches have shown significant effect on weight loss, although some are better in certain situations and provide additional benefits. The degree of weight loss is not significantly different in calorie restricted diet compared to diet with modified composition [41]. Based on available data, a balanced, low-calorie diet with healthy macronutrients, such as carbohydrate with low glycemic index $(\leq 55)$ and glycemic load $(\leq 10)$ per serving, fats rich in polyunsaturated fatty acids, and avoidance of saturated fatty acids, appears to be the first step to initiate lifestyle intervention [42].

\section{Calorie restriction approaches}

Low calorie diet (LCD): This conventional approach to lose weight restricts calorie intake to $1200 \mathrm{kcal}$ per day while maintaining standard proportions of nutrients to maintain a negative energy balance of $\geq$ $500 \mathrm{kcal} /$ day. Both short- and long-term efficacy of this approach has been well studied and compared with other approaches [29,39]. In a meta-analysis, mean weight loss was $9.8+4.5 \%$ with mean follow up of 38 weeks [43].

Very Low Calorie Diet (VLCD): A diet containing less than 1000 kcal per day is defined as VLCD. It has been studied and considered 
safe [44]. One study showed sustained beneficial metabolic effects 18 months after a diet of $450 \mathrm{kcal} /$ day for duration of 30 days in severely obese, insulin-treated patients with type 2 diabetes. Mean weight loss was $11.7 \mathrm{~kg}$ in 30 days (10.5\%) [45]. Other studies confirmed similar efficacy and also revealed improvement in visceral, in particular hepatic and subcutaneous, adiposity with reduction in liver volume and size $[44,46]$. This approach has shown some benefit in patients with morbid obesity prior to bariatric surgery in regard to both weight loss and fewer surgical complications [44].

\section{Modified dietary composition with or without calorie restriction approaches}

Low fat diet: This refers to a diet providing $\leq 30 \%$ of calories from fat. In the Women's Health Initiative Dietary Modification Trial, 48,835 postmenopausal women over age 50 years were randomly assigned to a dietary intervention that included group and individual counseling sessions that were intended to promote decreased fat intake and increased consumption of healthy carbohydrates. The study did not include weight loss or caloric restriction goals, and there was not a control group which received only dietary educational materials [47]. After an average of 7.5 years of follow-up, the study found that women in the intervention group not only lost weight in the first year (mean of $2.2 \mathrm{~kg}$ ), but they also maintained lower weight than the control group (difference of $1.9 \mathrm{~kg}$ at one year and $0.4 \mathrm{~kg}$ at 7.5 years). When compared with an iso caloric low carbohydrate diet, no significant difference was seen in weight lost [41]. However, the low carbohydrate diet resulted in better control of insulin resistance.

Carbohydrate restricted diet: Both quantity and quality of carbohydrate content of the diet are important determinants in weight loss and other metabolic factors. In a meta-analysis, reduced intake of dietary sugars was associated with a decrease in body weight [48]. Low (60 to 130 grams of carbohydrates) and very low-carbohydrate diets ( 0 to $<60$ grams) have been used in diabetic patients and have proven effective in weight reduction and improvement in metabolic parameters [49].

There is increasing evidence that postprandial hyperglycemia is an important risk factor for cardiovascular morbidity and mortality affecting the arterial wall through a number of mechanisms, including increased oxidative stress, endothelial dysfunction, and coagulation cascade activation [50]. Glycemic Index (GI) and Glycemic Load (GL) are measures that assess the responses of postprandial blood glucose and insulin to the intake of different carbohydrate-containing foods. GI is a measurement of how quickly blood sugar levels increase after eating a specific food as compared to a reference food such as white bread. The GL of food is a number that estimates the rise in blood glucose level after eating a particular food. In multiple prospective studies, lower levels of both GL and GI were associated with weight reduction, improved insulin sensitivity, and lower risk of cardiovascular disease and metabolic complications [51-54]. Some clinical trials have found greater weight loss with low GI diets than with conventional diets [55]. It has been proposed that low GI foods (e.g. whole grains) provide greater satiating efficiency than high GI foods (refined grains) [56].

High protein diet: $A \geq 25 \%$ of calorie intake from proteins is recommended in a high protein diet, which is suggested as a means of weight loss. There is no overall beneficial effect in terms of weight loss with high protein diet compared to a low calorie diet, although it provides some short-term benefit $[57,58]$. Detrimental effects of longterm intake of this approach have been reported [59-61].

Atkins and Modified Atkins Diet (MAD): The ketogenic diet
(KD) has been used since the 1920s to treat children with epilepsy who are resistant to Antiepileptic Drugs (AEDs). Its use in adolescents and adults has been less common. In recent decades, however, more liberal regimens have been developed that may appeal to older people [62].

The composition of the MAD was recently elaborated upon in a prospective, crossover-design evaluation [63]. The MAD was similar in fat composition to a 0.9:1 ketogenic ratio (fat: carbohydrate and protein) diet, with approximately $65 \%$ of the calories from fat sources. Adults are started at $15 \mathrm{~g}$ of carbohydrates/day and can be increased to $20-30 \mathrm{~g} /$ day after one month. All carbohydrates are allowed without regard to their glycemic index, and they can be given throughout the day or at one meal.

Mediterranean diet: The Mediterranean diet includes a high level of monounsaturated fat relative to saturated fat, moderate consumption of alcohol(mainly as wine), a high consumption of produce, legumes, and grains, a moderate consumption of dairy products (mostly in the form of cheese), and a relatively low intake of meat. In a meta-analysis, this diet had a significant effect on weight [mean difference between Mediterranean and control diets, $-1.75 \mathrm{~kg}]$ and BMI (mean difference, $-0.57 \mathrm{~kg} / \mathrm{m}^{2}$ ) [64]. No study reported significant weight gain with a Mediterranean diet. In another meta-analysis, greater adherence to a Mediterranean diet was associated with a significant improvement in health status, as seen by a significant reduction in overall mortality (9\%), mortality from cardiovascular diseases (9\%), incidence of or mortality from cancer (6\%), and incidence of Parkinson's disease and Alzheimer's disease (13\%). These results seem to be clinically relevant for public health, in particular for encouraging a similar dietary pattern for the primary prevention of major chronic diseases [65].

Commercial weight-loss programs: More than 25 commercial weight loss programs claiming significant weight loss exist in the US market [66]. A multi-center, randomized, controlled study of four such programs, in which adults were randomly allocated to one of the diets, showed a significant shift in the macronutrient composition and concurrent alteration of the micronutrient adequacy in all of the programs. There was no evidence to suggest micronutrient deficiency in subjects on any of the dietary regimens [67]. Another multi-center, randomized, controlled trial of the four diets above showed significant weight loss by all diet groups (5-9 kg at 6 months), but no significant difference was observed between diets at six months [68].

Others: Some intervention studies have suggested that dairy products may influence body weight. A meta-analysis does not support the beneficial effect of increasing dairy consumption on body weight and fat loss in long-term studies or studies without energy restriction. However, dairy products may have modest benefits in facilitating weight loss in short-term or energy-restricted Randomized Clinical Trials (RCTs) [69].

\section{Activity and Exercise: Role in Weight Loss}

Physical activity is the most (almost 25-30\%) variable of all components of TDEE [28]. It is the second component of lifestyle intervention, and it is recommended in conjunction with dietary regimen. A variety of factors have an impact on NEPA [70]. The US Department of Agriculture defines sedentary lifestyle as only light physical activity associated with typical day to day life. Moderate activity includes activity equivalent to walking $1.5-3$ miles per day in addition to daily activities, and active lifestyle is defined as activity equivalent to walking $>3$ miles per day in addition to daily activities [32]. At present, we do not have good tools to objectively assess activity in clinical practice. Pedometer is the only device that is 
available to monitor activity objectively in clinical practice, and it is of no use in patients with arthritis or a limited ability to walk, which is a common concurrent problem in patients with morbid obesity. A study has evaluated pedometer utility in defining sedentary lifestyle based on steps walked in day [71]. People walking $<5000$ steps in day are considered to have a sedentary lifestyle and are associated with increased cardio metabolic risks. Furthermore, there is little evidence to advocate any specific value indicative of a step-defined sedentary lifestyle index in children and adolescents. However, completing ten thousand or more steps per day is associated with improved metabolic factors and reduced cardiac risks.

Clinical efficacy of improved physical activity on weight loss and other parameters independent of dietary restrictions, such as insulin resistance, has been published and is well-established. Fitness and health variables were measured in 128 sedentary adults randomly assigned to six months of fitness training; a pedometer monitored walking program, or a control group [72]. Body mass, waist circumference, waist/hip ratio, and resting HR were reduced and fasting glucose, glucose tolerance, and total cholesterol improved in all groups $(\mathrm{p}<0.05)$. Improved activity has also been shown to improve weight loss and body composition in patients with bariatric surgery [73].

Improved activity in conjunction with dietary therapy is thought to work better than any approach alone and has been well-studied in a randomized clinical trial [18]. One group (initial physical activity) was randomized to diet and physical activity for one year; another group (delayed physical activity) had the identical dietary intervention but with physical activity delayed for six months. Although both intervention groups lost a significant amount of weight at six months, the initial-activity group lost significantly more weight in the first six months compared with the delayed-activity group. Weight loss at 12 months, however, was similar in the two groups. Waist circumference, visceral abdominal fat, hepatic fat content, blood pressure, and insulin resistance were all reduced in both groups. The addition of physical activity promoted greater reductions in waist circumference and hepatic fat content.

\section{Pharmacotherapy}

Anti-obesity drugs are an option for patients in whom lifestyle intervention is ineffective or insufficient. In patients with morbid obesity, bariatric surgery is the most effective treatment in terms of long-term weight loss, improvement in cardio metabolic risks and quality of life, and decline in overall mortality. Currently available options for the pharmacotherapy of obesity are very limited, especially in the setting of morbid obesity. This is not due to lack of interest or research on the subject but, rather, to the poor efficacy and/or safety profile of the majority of the anti-obesity drugs developed up to now. Long-term efficacy and safety of these medications are largely unknown. In past decades, various medications were brought to advanced stages of clinical development, but most of them never made it to the market or were withdrawn some years later because of safety issues. Various novel drug candidates and targets directed against obesity are currently being explored, and a few of them are in the later phases of clinical trials. Recently, state-of-the-art review articles have been published evaluating pharmacotherapy of obesity and efficacy of all published trials [74-76]. Anti-obesity medications provide modest additional fat loss to that achieved by lifestyle modification alone, reduce visceral fat stores, improve program adherence and weight loss maintenance, diminish obesity-related health risks, and improve quality of life. The mean weight loss associated with medications ranged from $1.9 \mathrm{~kg}$ to 9.6 $\mathrm{kg}$ over a period of 13 to 56 weeks. Combination treatment appears to result in more weight loss than monotherapy.

Understanding of the pathophysiology mechanism, in particular neuroendocrine regulation of obesity, has been steadily increasing and new, promising drugs targeting various selected energy-homeostasisrelated pathways are now under development. Increasing the activity of the right Prefrontal Cortex (PFC) might decrease appetite and reestablish inhibitory mechanisms controlling eating as well as improve long-term adherence to interventions such as diet or exercise therapy, which is a major barrier that limits the success of any attempt to treat obesity.

\section{Surgical Treatment}

Bariatric surgery is considered the only effective intervention for morbid obesity that consistently induces sustained weight loss with proven long-term outcomes [77]. The results are superior to those from a combination of diet, exercise, and behavioral modification, with or without pharmacology [78,79]. Moreover, bariatric surgical procedures greatly improve comorbidities, even before weight loss is achieved due to the anatomical and hormonal changes in the gastrointestinal tract [80-82], and reduce mortality $[83,84]$.

The number of bariatric procedures performed in the US increased from 13,386 in 1998 to 220,000 in 2008. Worldwide, 344,000 bariatric surgeries are performed annually. Roux-en- $Y$ gastric bypass is the most common procedure (54.7\% US; $47 \%$ worldwide), followed by Laparoscopic Adjustable Gastric Banding (LAGB) (39.6\% and $42 \%)$, laparoscopic sleeve gastrectomy (LSG) $(2.3 \%$ and $5 \%)$ and bilio pancreatic bypass/duodenal switch (BPB/DS) (0.9\% and $2 \%)$ $[85,86]$. Despite these increasing numbers and its proven efficacy for the treatment of morbid obesity, less than $1 \%$ of the patients who require bariatric surgery meet the National Institutes of Health $(\mathrm{NIH})$ guidelines [87].

\section{Indications and contraindications}

Most of the clinical guidelines regarding the indications of bariatric surgery for the treatment of morbid obesity follow the recommendations resulting from the Consensus Development Conference on gastrointestinal surgery for severe obesity convoked in 1991 by the NIH [88]. In that conference, the including criteria were:

- $\quad B M I \geq 40 \mathrm{~kg} / \mathrm{m}^{2}$

- $\quad$ BMI $\geq 35 \mathrm{~kg} / \mathrm{m}^{2}$ in patients with high-risk conditions, such as severe sleep apnea, obesity-related cardiomyopathy, or severe diabetes mellitus

- All patients must document previous failure of nonsurgical weight loss attempts

As a consequence of newer evidence that supports the benefits in a wider range of patients, the American Society for Metabolic and Bariatric Surgery (ASMBS) consensus conference in 2004 extended the indication to patients with class I obesity (BMI 30 to $34.9 \mathrm{~kg} / \mathrm{m}^{2}$ ) with major obesity-related comorbidities [89].

The indications for bariatric surgery are still undefined for certain populations like super-super obese patients (BMI $\left.\geq 60 \mathrm{~kg} / \mathrm{m}^{2}\right)$, patients outside the commonly defined age ranges (younger than 18 and older than 60), and obese patients requiring weight loss in preparation for other surgical procedures.

Few contraindications exist for bariatric surgery and comprise 
mental or cognitive impairment that limits the patient's ability to understand and consent to the procedure and to complete a regular follow-up. Additional contraindications include extremely severe medical conditions that constitute an unacceptable high risk for the surgery.

\section{Preoperative evaluation}

Preoperative evaluation for bariatric surgery needs to be carried out by a multidisciplinary team, including specialized nurses, dietitians, psychiatrists, cardiologists, respiratory physicians, endocrinologists and bariatric surgeons. It should include a detailed nutritional and weight history, with previous attempts to lose weight and the reasons that prevented the success; a history of medication intake; discharge secondary causes of obesity; and it should include a psychological evaluation to determine associated psychiatric disorders, disturbed eating habits, substance abuse, social support and surgical expectations. All of these factors are going to influence directly the results of the procedure in terms of weight loss.

The presence of co morbid conditions that are common with morbid obesity must be carefully evaluated and controlled before surgery to reduce their impact during the postoperative period. It is important to provide a baseline to determine the outcomes of the bariatric procedure.

\section{Types of procedures}

Bariatric surgical procedures reduce caloric intake by modifying the anatomy of the gastrointestinal tract. They are classified by the mechanism through which they achieve this reduction: malabsorptive, restrictive and combined malabsorptive and restrictive (Figure 1). There is no superior bariatric surgical procedure; all of them have advantages and disadvantages (Table 1). The appropriate selection of a procedure should be tailored to each individual patient.

\section{Biliopancreatic diversion/duodenal switch}

The Biliopancreatic Diversion (BPD) procedure achieves weight loss primarily through malabsorption as a result of an increased gastric emptying rate and accelerated intestinal transit times [90]. The procedure comprises a partial gastrectomy with closure of the duodenal stump. The small intestine is divided at the midpoint between the ligament of Treitz and the ileocecal valve to create a Roux-en-Y gastroenterostomy. The enteroileostomy leaves a $50-\mathrm{cm}$ tube to the ileocecal valve. Subsequent modifications of the original technique were introduced in order to reduce the occurrence of the so-called post-gastrectomy syndrome that invariably results from this procedure and which includes marginal ulceration, early and late dumping, diarrhea and nutritional deficiencies. By preserving the pylorus, gastric emptying problems and the presence of dumping were eliminated.

The addition of the Duodenal Switches (DS), described by Hess, includes a vertical Sleeve Gastrectomy (SG) with pylorus preservation and division of the duodenum just distal to the pylorus [91]. The stomach pouch has a capacity of $250 \mathrm{ml}$, and mal absorption results from a distal Roux-en-Y reconstruction of the bowel with a common channel of 50 to $100 \mathrm{~cm}$ and an alimentary tube of $250 \mathrm{~cm}$. Unlike the BPD procedure, this technique does not cause marginal ulcers and dumping syndrome. The DS version achieves normal filling of the gastric remnant, conserving the sensation of satiety. The SG provides a reduction of the parietal cell mass and an additional restrictive component that increase weight loss.

\section{Adjustable gastric banding}

The Adjustable Gastric Band (AGB) was first described by Forcell et al. in Sweden in 1985 [92]. This procedure is routinely done laparoscopically and is considered the least invasive bariatric surgical procedure due to the lack of disruption of the gastrointestinal tract. The AGB implies the creation of a small virtual gastric pouch by placing a silicone band around the upper stomach $1-2 \mathrm{~cm}$ below the gastro esophageal junction, which is connected with a subcutaneous port that allows access. A small retro gastric tunnel is created large enough for the band to pass through, and stitches are placed anteriorly from the greater curvature to above the band to avoid later slippages [93]. Postoperatively, by injecting saline fluids through the port, the balloon volume could be adjusted, varying the degree of constriction of the stomach and, as a consequence, its capacity. Also, the gastric outlet is calibrated; therefore, satiety will be prolonged. This procedure is completely reversible but requires close follow-up to perform the adjustments and, by that means, good outcomes.

\section{Sleeve gastrectomy}

Sleeve Gastrectomy (SG) was originally described as the restrictive component of the BPD/DS by Marceau and colleagues in 1998 [94]. The procedure involves a vertical gastrectomy performed with linear staplers, which is then over sewn; that excises the most compliant part of the stomach, the fundus and lateral $80 \%$ of the body, leaving a narrow gastric tube with preservation of the antrum and the pylorus. The removal of the greater curvature of the stomach results in a reduced risk of subsequent dilation, and the removal of the ghrelinproducing cell mass increases long-term weight reduction. Some of the patients that were initially selected for duodenal switch could not undergo the intestinal bypass step even though they experienced excellent weight loss after SG alone. Following this finding, the surgery was developed into a two-stage procedure as a bridge to a definitive treatment in super-obese and high-risk patients [95]. As a consequence of the good outcomes and supporting data in terms of weight loss and improvement of comorbidities, SG has gained popularity as a primary bariatric procedure with the possibility of a second-stage gastric bypass

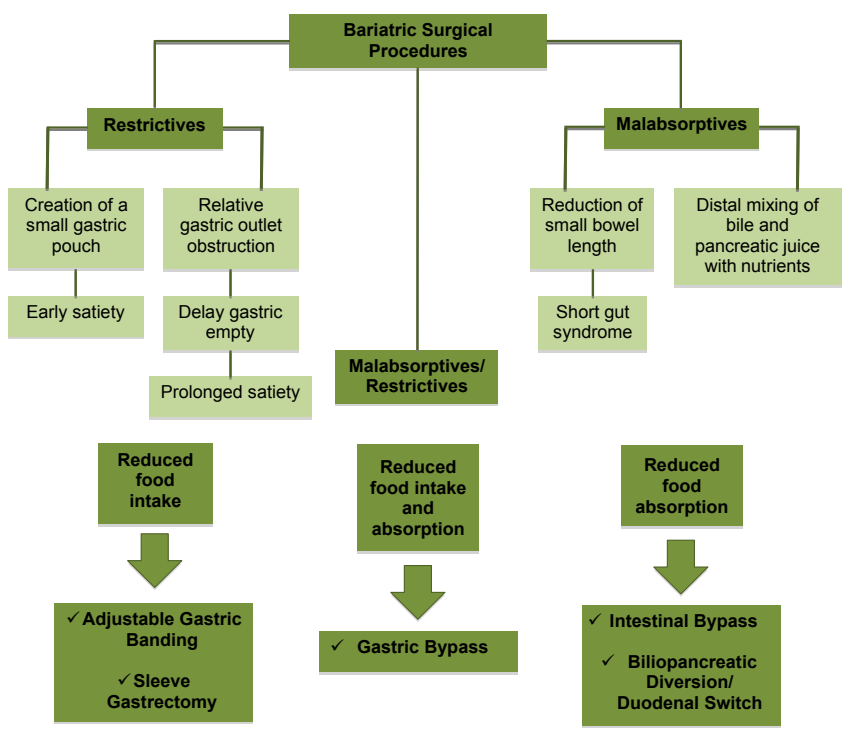

Eating behavioral modifications Hormonal and neural changes

Figure 1: Types and Mechanisms of Action of Surgical Bariatric Procedures. 


\begin{tabular}{|c|c|}
\hline Advantages & Disadvantages \\
\hline \multicolumn{2}{|c|}{ Laparoscopic Adjustable Gastric Banding } \\
\hline - $\quad$ Fewer perioperative risks & - $\quad$ Complex follow-up (band adjustments) \\
\hline - $\quad$ Outpatient surgery & - $\quad$ Requires high commitment from the patient \\
\hline - Reversibility & - High risk of reoperations \\
\hline - $\quad$ No metabolic complications & - $\quad$ Reduced maintenance of weight loss \\
\hline \multicolumn{2}{|c|}{ Sleeve Gastrectomy } \\
\hline - $\quad$ Super-obese, high risk and older patients & - $\quad$ Long stapler line \\
\hline - Multi operate abdomens & - Irreversibility \\
\hline - Does not need an implantable device & - Vitamin B12 deficiency \\
\hline - Low incidence of complications and mortality & \\
\hline - $\quad$ Reduced metabolic complications & \\
\hline - $\quad$ Long-term weight loss & \\
\hline - Resolution of comorbidities & \\
\hline - $\quad$ Minimized ulcerogenity & \\
\hline \multicolumn{2}{|c|}{ Roux-en-Y Gastric Bypass } \\
\hline - $\quad$ Faster weight loss & - Technically complex \\
\hline - $\quad$ Simpler follow-up & - Irreversibility \\
\hline \multirow[t]{2}{*}{ - Does not need an implantable device } & - High risk of short-term complications \\
\hline & - High incidence of dumping syndrome \\
\hline \multicolumn{2}{|c|}{ Biliopancreatic Diversion \pm Duodenal Switch } \\
\hline - Greater weight reduction & - $\quad$ Major abdominal surgery \\
\hline - $\quad$ Best results in resolution of comorbidities & - High incidence of long-term complications \\
\hline \multirow[t]{3}{*}{ - Does not need an implantable device } & - Malabsorptive syndrome \\
\hline & - $\quad$ Nutrients and vitamins deficiencies \\
\hline & - Irreversibility \\
\hline
\end{tabular}

Table 1: Advantages and Disadvantages of Bariatric Procedures.

or duodenal switch in patients with weight regain or inadequate weight loss after laparoscopic sleeve gastrectomy [96-98]. It is also is a procedure that could be offered to patients with inflammatory bowel syndrome.

\section{Roux-en-Y gastric bypass}

Gastric Bypass (GB) was first performed by Mason and Ito in 1966 in response to the detrimental side effects observed with jejunoileal bypass [99], introducing gastric restriction as the main mechanism to achieve weight loss. The procedure has evolved over the 30 years following its initial description to include multiple modifications, becoming the most commonly bariatric surgery performed in the US. It is considered the criterion standard because of its greater weight loss and lower weight regain when compared with other bariatric surgical procedures. The current technique involves the creation of a small gastric pouch (less than $30 \mathrm{ml}$ ), a small gastro jejunostomy of approximately $12 \mathrm{~mm}$ in diameter, and a Roux-en-Y configuration of the alimentary limb that ranges from 60 to $250 \mathrm{~cm}$ in length. With the increase in the performance of laparoscopic gastric bypass, which in 2004 surpassed the number of open procedures [100], the effect of these modifications constituted an extensive theme of study. Current variations in the surgical technique include the method by which the gastric pouch is created, the technique of gastro jejunostomy, and the configuration and length of the alimentary and biliopancreatic limbs [101-104].

\section{Bariatric surgery outcomes}

7.8.1. Weight loss: In 2009, Cochrane published a review of bariatric surgery that included 26 studies; from them, there were three RCTs and three prospective cohort studies comparing surgery with non-surgical interventions. It also included 20 RCTs comparing different bariatric procedures. The authors concluded that surgery results in greater weight loss than conventional treatment [78]. The systematic review, published by Health Technology Assessment, arrived to the same conclusion. The mean percentage of initial weight loss was $20 \%$ and $21.6 \%$ compared with $1.4 \%$ and $5.5 \%$ in the non-surgical groups of the two RCTs that reported their outcomes at two years. The two cohort studies included on that analysis reported $16 \%$ to $28.6 \%$ weight change for the bariatric surgery groups but weight gain in the non-surgical groups with a percentage weight change ranging from $0.1 \%$ to $0.5 \%$ [77]. A large, non-randomized controlled intervention trial, known as the SOS study, involved 4047 patients with a mean follow-up of $10.9 \pm$ 3.5 years. It revealed that the greater weight loss achieved with bariatric surgery was still apparent after 10 years following surgery, whereas the non-surgical group gained weight [105].

By comparing bariatric procedures, we can conclude that certain procedures obtain greater weight loss; however, they have different profiles that make it difficult to achieve strong conclusions, and the data is limited and sometimes equivocal.

The systematic review and meta-analysis published by Buchwald et al. [89] in 2004 reported an excess weight loss of $47.5 \%$ for AGB, $61.6 \%$ for GB, $68.2 \%$ for gastroplasty and $70.1 \%$ for BPD or DS [105]. The Health Technology Assessment, which included SG in its analysis, found that gastric bypass was more effective than vertical banded gastroplasty and adjustable gastric band for weight loss and that SG had better results than AGB [77].

Comorbidities: Improvement or resolution of comorbidities after bariatric surgery was observed in five RTCs with no significant differences between bariatric procedures [77]. Buchwald et al. [89] found that medical conditions resolved or significantly improved, respectively, in $76.8 \%$ and $86 \%$ for $\mathrm{T} 2 \mathrm{DM}, 61.7 \%$ and $78.5 \%$ for hypertension, and $85.7 \%$ and $83.6 \%$ for sleep apnea [105].

Two RTCs included in the Health Technology Assessment systematic review revealed a reduction in the number of patients with 
metabolic syndrome and higher remission of T2DM in the surgical group compared with non-surgical management [77].

The SOS study showed a statistically significant reduction in the incidence of three out of six comorbidities assessed at 10 years after surgery compared with conventional therapy [105].

Survival: Survival is significantly increased in morbidly obese patients after bariatric surgery. A meta-analysis including eight trials (44,022 patients) published by Pontiroli and Morabito [106] showed a reduced risk of global mortality, cardiovascular mortality, and mortality of all causes after surgery compared with controls. Similarly, results from the SOS study revealed that, compared to usual care, bariatric surgery was associated with a long-term reduction in overall mortality, which was the primary end point of the study, and decreased incidences of T2DM, myocardial infarction, stroke and cancer [107]. Even when the risks of death associated with surgery are taken into account, patients who have surgery are more likely to be alive at one year after surgery than patients who chose conservative treatment [108].

\section{Complications of Bariatric Surgery}

With the increased number of bariatric procedures performed in the early 2000s, published outcomes appeared to be inconsistent, with some surgeons and centers achieving good short- and long-term results and others showing high complication and mortality rates. Several studies demonstrated that the likelihood of complications was significantly related with annual surgical experience $[109,110]$. In order to provide a mechanism to improve and unify the safety and efficacy of bariatric surgical care, the ASMBS and the American College of Surgeons established certain criteria that centers and surgeons must to meet in order to be accredited as bariatric surgical centers of excellence.

Currently, complication rates are relatively low, occurring in approximately $4.1 \%$ of the procedures [86]. Most common perioperative complications include venous thromboembolism, respiratory insufficiency, anastomotic leaks, bleeding, wound infections, early small-bowel obstruction and internal hernias. The type of procedure and the special characteristics of the patients subject to bariatric surgery directly influence the occurrence of complications (Table 2). Overall complication rates depending on the type of procedure were $9 \%$ for laparoscopic AGB, 23\% for RYGB, 25\% for laparoscopic BPD/DS, and $11.2 \%$ for laparoscopic SG [111]. History of deep vein thrombosis or pulmonary embolism, obstructive sleep apnea, impaired functional status, and extreme values of BMI are the characteristics related to increased risk of developing major complications [110].

Gastrointestinal complications are by far the most common. Nausea and vomiting are frequent in restrictive procedures as a consequence of patients eating behaviors or because of an astomotic stricture. Dumping syndrome occur in almost $70 \%$ of patients after RYGB. Nutritional deficits follow malabsorptive procedures. Iron, calcium, folate and vitamin B12 deficiencies are present in gastric bypass. With $\mathrm{BPD} / \mathrm{DS}$, the deficit extends to protein malnutrition and fat-soluble vitamins.

\section{Mortality}

Perioperative mortality rates have been improving. Buchwald et al. [112] reported early (30-days) and late (two-year) mortality in a metaanalysis of 85,498 patients from 361 studies published between 1990 and 2006 . The rates were $0.28 \%$ and $0.35 \%$, respectively. In comparison, the BOLD database, published in 2010, reported 78 deaths of 57,918 patients and a 30-day mortality of $0.09 \%$ [86].
Thirty-day mortality rates for different types of open and laparoscopic bariatric procedures were $0.3 \%$ and $0.07 \%$ for restrictive procedures, $0.41 \%$ and $0.16 \%$ for restrictive/malabsorptive procedures, and $0.76 \%$ and $1.11 \%$ for malabsorptive procedures. Noteworthy was that the better results accomplished with laparoscopic approach were not reflected in malabsorptive procedures [112].

Some contributions to reduced mortality were the widespread use of laparoscopic approach, better anesthesia and monitoring, and an increased control of the centers performing bariatric surgery as a result of the BSCOE (Bariatric Surgery Centers of Excellence) implementation [86].

Factors related to increased mortality was visceral obesity, male sex, severe obesity (BMI $\geq 50$ ), presence of comorbidities such as diabetes mellitus and obstructive sleep apnea, advanced age, and lack of experience of the surgeon or the program [86].

\section{The role of robotics in bariatric surgery}

Without any doubt, the best contribution for the improvement of bariatric surgery was the introduction of laparoscopy. Despite a learning curve, surgical outcomes improved over time, equating and then surpassing the results obtained during the open bariatric era. The reduction in the occurrence of postoperative complications and the shorter lengths of stay and recovery promptly resulted in an increased demand for laparoscopic bariatric procedures.

In 2006, laparoscopic procedures represented $83.2 \%$ of all bariatric surgeries, ascending to $88.9 \%$ in 2008 [86].

Laparoscopic Adjustable Gastric Banding

- Esophageal or gastric perforation

- Band slippage/migration

- Obstruction

- Band erosion

- Hiatal hernia

- Dysphagia

- Pouch dilation

- Port site infection

- Staple line disruption/Leaks

- Bleeding (staple line, short gastric vessels, spleen, omental vessels)

- Strictures

- Chronic fistula

- Gastroesophageal reflux disease

Roux-en-Y Gastric Bypass

- Anastomotic leaks

- Gastrointestinal tract bleeding

- Bowel obstruction

- Internal hernias

- Anastomotic strictures

- Marginal ulcerations

Biliopancreatic Diversion \pm Duodenal Switch

- Leaks

- Gastrointestinal tract bleeding

- Chronic diarrhea/Steatorrhea

- Protein malnutrition

- Fat-soluble vitamins deficiency

- Anemia

- Kidney stones

- Bone demineralization

Table 2: Specific Complications According to the Bariatric Procedure. 
The most significant impact of robotically assisted surgery was the possibility to extend the already well-known benefits achieved with minimally invasive surgery to difficult procedures often performed in an open manner. Its application in bariatric surgery contributed to amplifying the benefits of minimally invasive access without increasing complication risks as a result of the learning curve.

The first bariatric procedure with robotic assistance was an adjustable gastric banding reported in 1999 [113], and in 2001, Horgan and Vanuno reported the first robotic-assisted gastric bypass [114].

One of the major advantages of the use of robotic technology for bariatric surgery is the facilitated completion of hand-sewn gastrointestinal an astomosis, which notably reduces the risk of leaks and an astomotic strictures.

These benefits were reflected in a systematic review of roboticassisted bariatric surgery published in 2011, which included 22 studies with 1253 patients. No deaths were observed, and they found a reduction in anastomotic leaks, stenosis and bleeding rates. The major disadvantage is the same as with other procedures, and there are higher operational costs than with laparoscopic surgeries [115].

\section{Conclusion}

Morbid obesity its serious comorbidities, reduction of quality of life, and mortality is a worldwide health problem that is raising exponentially. Weight loss, regardless of treatment modality, has shown improvement in obesity-related morbidity and mortality. Always lifestyle intervention is the first step in the treatment of morbid obesity and remains as important when pharmacotherapy and surgical treatment of morbid obesity are to be implemented. A multidisciplinary team approach including a comprehensive medical, nutritional, psychological and surgical evaluation and management determine the best outcome of treatment of morbid obesity. Bariatric surgery is currently the only effective treatment with long-term results for the treatment of morbid obesity, resolution of comorbidities, and improved life expectancy.

\section{Acknowledgement}

Authors wish to thank Delfina Gaxiola for her help in preparation of manuscript.

\section{References}

1. Crovetto M, Uauy $R$ (2012) [Changes in processed food expenditure in the population of Metropolitan Santiago in the last twenty years]. Rev Med Chil 140: 305-312.

2. Malik VS, Hu FB (2012) Sweeteners and Risk of Obesity and Type 2 Diabetes: The Role of Sugar-Sweetened Beverages. Curr Diab Rep .

3. Bremer AA, Byrd RS, Auinger P (2011) Racial trends in sugar-sweetened beverage consumption among US adolescents: 1988-2004. Int J Adolesc Med Health 23: 279-286.

4. Mokdad AH, Ford ES, Bowman BA, Dietz WH, Vinicor F, et al. (2003) Prevalence of obesity, diabetes, and obesity-related health risk factors, 2001. JAMA 289: 76-79.

5. Flegal KM, Carroll MD, Kit BK, Ogden CL (2012) Prevalence of obesity and trends in the distribution of body mass index among US adults, 1999-2010. JAMA 307:491.

6. Field AE, Coakley EH, Must A, Spadano JL, Laird N, et al. (2001) Impact of overweight on the risk of developing common chronic diseases during a 10year period. Arch Intern Med 161: 1581-1586.

7. Colditz GA, Willett WC, Rotnitzky A, Manson JE (1995) Weight gain as a risk factor for clinical diabetes mellitus in women. Ann Intern Med 122: 481-486.

8. Johnson RJ, Gold MS, Johnson DR, Ishimoto T, Lanaspa MA, et al. (2011) Attention-deficit/hyperactivity disorder: is it time to reappraise the role of sugar consumption? Postgrad Med 123: 39-49.
9. Flegal KM, Kit BK, Orpana H, Graubard BI (2013) Association of all-cause mortality with overweight and obesity using standard body mass index categories: a systematic review and meta-analysis. JAMA 309: 71-82.

10. Whitlock G, Lewington S, Sherliker P, Clarke R, Emberson J, et al. (2009) Body-mass index and cause-specific mortality in 900000 adults: collaborative analyses of 57 prospective studies. Lancet 373:1083.

11. Finkelstein EA, Trogdon JG, Cohen JW, Dietz W (2009) Annual medical spending attributable to obesity: payer-and service-specific estimates. Health Aff (Millwood) 28: w822-831.

12. Huang ES, Basu A, O'Grady M, Capretta JC (2009) Projecting the future diabetes population size and related costs for the U.S. Diabetes Care 32: 22252229.

13. Lal A, Moodie M, Ashton T, Siahpush M, Swinburn B (2012) Health care and lost productivity costs of overweight and obesity in New Zealand. Aust N Z J Public Health 36: 550-556.

14. Xenachis C, Samojlik E, Raghuwanshi MP, Kirschner MA (2001) Leptin, insulin and TNF-alpha in weight loss. J Endocrinol Invest 24: 865-870.

15. Neter JE, Stam BE, Kok FJ, Grobbee DE, Geleijnse JM (2003) Influence of weight reduction on blood pressure: a meta-analysis of randomized controlled trials. Hypertension 42: 878-884.

16. Sjöström L, Lindroos AK, Peltonen M, Torgerson J, Bouchard C, et al. (2004) Swedish Obese Subjects Study Scientific Group. Lifestyle, diabetes, and cardiovascular risk factors 10 years after bariatric surgery. N Engl J Med 351:2683.

17. Campbell KL, Van Patten CL, Neil SE, Kirkham AA, Gotay CC, et al. (2012) Feasibility of a lifestyle intervention on body weight and serum biomarkers in breast cancer survivors with overweight and obesity. J Acad Nutr Diet 112 559-567.

18. Goodpaster BH, Delany JP, Otto AD, Kuller L, Vockley J, et al. (2010) Effects of diet and physical activity interventions on weight loss and cardiometabolic risk factors in severely obese adults: a randomized trial. JAMA 304: 1795-1802.

19. Colles SL, Dixon JB, Marks P, Strauss BJ, O'Brien PE (2006) Preoperative weight loss with a very-low-energy diet: quantitation of changes in liver and abdominal fat by serial imaging. Am J Clin Nutr 84: 304-311.

20. Kissler HJ, Settmacher U (2013) Bariatric surgery to treat obesity. Semin Nephrol 33: 75-89.

21. Melendez-Araújo MS, de Matos Arruda SL, de Oliveira Kelly E, de Carvalho KM (2012) Preoperative nutritional interventions in morbid obesity: impact on body weight, energy intake, and eating quality. Obes Surg 22: 1848-1854.

22. Weck M, Bornstein SR, Barthel A, Blüher M (2012) [Strategies for successful weight reduction - focus on energy balance]. Dtsch Med Wochenschr 137 2223-2228.

23. Westerterp KR (2008) Physical activity as determinant of daily energy expenditure. Physiol Behav 93: 1039-1043.

24. Donahoo WT, Levine JA, Melanson EL (2004) Variability in energy expenditure and its components. Curr Opin Clin Nutr Metab Care 7: 599-605.

25. Cornu M, Albert V, Hall MN (2013) mTOR in aging, metabolism, and cancer Curr Opin Genet Dev 23: 53-62.

26. Johannsen DL, Knuth ND, Huizenga R, Rood JC, Ravussin E, et al. (2012) Metabolic slowing with massive weight loss despite preservation of fat-free mass. J Clin Endocrinol Metab 97:2489-2496.

27. Unick JL, Beavers D, Bond DS, Clark JM, Jakicic JM, et al. (2013) The longterm effectiveness of a lifestyle intervention in severely obese individuals. Am J Med 126: 236-242, 242

28. Gill RS, Karmali S, Hadi G, Al-Adra DP, Shi X, et al. (2012) Predictors of attrition in a multidisciplinary adult weight management clinic. Can J Surg 55: 239-243.

29. Stern L, Iqbal N, Seshadri P, Chicano KL, Daily DA, et al. (2004) The effects of low-carbohydrate versus conventional weight loss diets in severely obese adults: one-year follow-up of a randomized trial. Ann Intern Med 140: 778-785.

30. Alonso-Alonso M, Pascual-Leone A (2007) The right brain hypothesis for obesity. JAMA 297: 1819-1822.

31. Zhu K, Wu H, Jatoi I, Potter J, Shriver C (2006) Body mass index and use of mammography screening in the United States. Prev Med 42: 381-385.

32. Carels RA, Young KM, Hinman N, Gumble A, Koball A, et al. (2012) 
Stepped-care in obesity treatment: matching treatment intensity to participant performance. Eat Behav 13: 112-118.

33. Nijamkin MP, Campa A, Sosa J, Baum M, Himburg S, et al. (2012) Comprehensive nutrition and lifestyle education improves weight loss and physical activity in Hispanic Americans following gastric bypass surgery: a randomized controlled trial. J Acad Nutr Diet 112:382-390.

34. Parikh M, Dasari M, McMacken M, Ren C, Fielding G, et al. (2012) Does a preoperative medically supervised weight loss program improve bariatric surgery outcomes? A pilot randomized study. Surg Endosc 26: 853-861.

35. Ross R, Lam M, Blair SN, Church TS, Godwin M, et al. (2012) Trial of prevention and reduction of obesity through active living in clinical settings: a randomized controlled trial. Arch Intern Med 172: 414-424.

36. Kullgren JT, Troxel AB, Loewenstein G, Asch DA, Norton LA, et al. (2013) Individual- versus group-based financial incentives for weight loss: a randomized, controlled trial. Ann Intern Med 158: 505-514.

37. Karasu SR (2013) Psychotherapy-lite: obesity and the role of the mental health practitioner. Am J Psychother 67: 3-22.

38. de Niet J, Timman R, Bauer S, van den Akker E, Buijks H, et al. (2012) The effect of a short message service maintenance treatment on body mass index and psychological well-being in overweight and obese children: a randomized controlled trial. Pediatr Obes 7: 205-219.

39. Pagoto S, Schneider KL, Whited MC, Oleski JL, Merriam P, et al. (2013) Randomized controlled trial of behavioral treatment for comorbid obesity and depression in women: the Be Active Trial. Int J Obes (Lond) .

40. Jang Y, Noh HW, Lee IB, Song Y, Jang WI, et al. (2011) Development of an integrated obesity management waist belt system composed of calorie tracking and waist circumference measuring module for long term monitoring. Conf Proc IEEE Eng Med Biol Soc 2011:2172-2175.

41. Triffoni-Melo Ade T, Dick-de-Paula I, Portari GV, Jordao AA, Garcia Chiarello P et al. (2011) Short-term carbohydrate-restricted diet for weight loss in severely obese women. Obes Surg 21: 1194-1202.

42. McGuire S (2011) U.S. Department of Agriculture and U.S. Department of Health and Human Services, Dietary Guidelines for Americans, 2010. 7th Edition, Washington, DC: U.S. Government Printing Office, January 2011. Adv Nutr 2: 293-294.

43. Corona G, Rastrelli G, Monami M, Saad F, Luconi M, et al. (2013) Body weight loss reverts obesity-associated hypogonadotropic hypogonadism: a systematic review and meta-analysis. Eur J Endocrinol 168: 829-843.

44. Sumithran P, Proietto J (2008) Safe year-long use of a very-low-calorie diet for the treatment of severe obesity. Med J Aust 188: 366-368.

45. Jazet IM. de Craen AJ. vanSchie EM. Meinders AE (2007) Sustained beneficial metabolic effects 18 months after a 30-day very low calorie diet in severely obese, insulin-treated patients with type 2 diabetes. Diabetes Research \& Clinical Practice 77:70-6.

46. Lewis MC, Phillips ML, Slavotinek JP, Kow L, Thompson CH, et al. (2006) Change in liver size and fat content after treatment with Optifast very low calorie diet. Obes Surg 16: 697-701.

47. Howard BV, Manson JE, Stefanick ML, Beresford SA, Frank G, et al. (2006) Low-fat dietary pattern and weight change over 7 years: the Women's Health Initiative Dietary Modification Trial. JAMA 295: 39-49.

48. Te Morenga L, Mallard S, Mann J (2012) Dietary sugars and body weight: systematic review and meta-analyses of randomised controlled trials and cohort studies. BMJ 346: e7492.

49. Brinkworth GD, Noakes M, Buckley JD, Keogh JB, Clifton PM (2009) Long-term effects of a very-low-carbohydrate weight loss diet compared with an isocaloric low-fat diet after 12 mo. Am J Clin Nutr 90: 23-32.

50. Hu Y, Block G, Sternfeld B, Sowers M (2009) Dietary glycemic load, glycemic index, and associated factors in a multiethnic cohort of midlife women. $\mathrm{J} \mathrm{Am}$ Coll Nutr 28: 636-647.

51. Liu S, Willett WC, Stampfer MJ, Hu FB, Franz M, et al. (2000) A prospective study of dietary glycemic load, carbohydrate intake, and risk of coronary heart disease in US women. Am J Clin Nutr 71: 1455-1461.

52. Salmerón J, Ascherio A, Rimm EB, Colditz GA, Spiegelman D, et al. (1997) Dietary fiber, glycemic load, and risk of NIDDM in men. Diabetes Care 20: $545-550$.
53. Barclay AW, Brand-Miller JC, Wolever TM (2005) Glycemic index, glycemic load, and glycemic response are not the same. Diabetes Care 28: 1839-1840.

54. Ajala O, English P, Pinkney J (2013) Systematic review and meta-analysis of different dietary approaches to the management of type 2 diabetes. Am J Clin Nutr 97: 505-516.

55. McMillan-Price J, Petocz P, Atkinson F, O'neill K, Samman S, et al. (2006) Comparison of 4 diets of varying glycemic load on weight loss and cardiovascular risk reduction in overweight and obese young adults: a randomized controlled trial. Arch Intern Med 166: 1466-1475.

56. Maki KC, Rains TM, Kaden VN, Raneri KR, Davidson MH (2007) Effects of a reduced-glycemic-load diet on body weight, body composition, and cardiovascular disease risk markers in overweight and obese adults. Am J Clin Nutr 85: 724-734.

57. Rolland-Cachera MF, Thibault H., Souberbielle JC, Soulie D, Carbonel P, et al (2004) Massive obesity in adolescents: dietary interventions and behaviours associated with weight regain at $2 \mathrm{y}$ follow-up. International Journal of Obesity \& Related Metabolic Disorders: Journal of the International Association for the Study of Obesity $28: 514-519$

58. Due A, Toubro S, Skov AR, Astrup A (2004) Effect of normal-fat diets, either medium or high in protein, on body weight in overweight subjects: a randomised 1-year trial. Int J Obes Relat Metab Disord 28: 1283-1290.

59. Ince BA, Anderson EJ, Neer RM (2004) Lowering dietary protein to U.S Recommended dietary allowance levels reduces urinary calcium excretion and bone resorption in young women. J Clin Endocrinol Metab 89: 3801-3807.

60. Dawson-Hughes B, Harris SS, Rasmussen H, Song L, Dallal GE (2004) Effect of dietary protein supplements on calcium excretion in healthy older men and women. J Clin Endocrinol Metab 89: 1169-1173.

61. Kerstetter JE, O'Brien KO, Caseria DM, Wall DE, Insogna KL (2005) The impact of dietary protein on calcium absorption and kinetic measures of bone turnover in women. J Clin Endocrinol Metab 90: 26-31.

62. Payne NE, Cross JH, Sander JW, Sisodiya SM (2011) The ketogenic and related diets in adolescents and adults--a review. Epilepsia 52: 1941-1948.

63. Kossoff EH, Dorward JL (2008) The modified Atkins diet. Epilepsia 49 Supp 8: $37-41$.

64. Esposito K, Kastorini CM, Panagiotakos DB, Giugliano D (2011) Mediterranean diet and weight loss: meta-analysis of randomized controlled trials. Metab Syndr Relat Disord 9: 1-12.

65. Sofi F, Cesari F, Abbate R, Gensini GF, Casini A (2008) Adherence to Mediterranean diet and health status: meta-analysis. BMJ 337: a1344.

66. http://health.usnews.com/best-diet/best-weight-loss-diets

67. Truby H, Hiscutt R, Herriot AM, Stanley M, Delooy A, et al. (2008) Commercia weight loss diets meet nutrient requirements in free living adults over 8 weeks: a randomised controlled weight loss trial. Nutr J 7: 25.

68. Morgan LM, Griffin BA, Millward DJ, DeLooy A, Fox KR, et al. (2009) Comparison of the effects of four commercially available weight-loss programmes on lipidbased cardiovascular risk factors. Public Health Nutr 12: 799-807.

69. Chen M, Pan A, Malik VS, Hu FB (2012) Effects of dairy intake on body weigh and fat: a meta-analysis of randomized controlled trials. Am J Clin Nutr 96: 735-747.

70. Kahan D (2009) Quantity, type, and correlates of physical activity among American Middle Eastern university students. Res Q Exerc Sport 80: 412-423.

71. Tudor-Locke C, Craig CL, Thyfault JP, Spence JC (2013) A step-defined sedentary lifestyle index: $<5000$ steps/day. Appl Physiol Nutr Metab 38: 100 114

72. Bell GJ, Harber V, Murray T, Courneya KS, Rodgers W (2010) A comparison of fitness training to a pedometer-based walking program matched for total energy cost. J Phys Act Health 7: 203-213.

73. Egberts K, Brown WA, Brennan L, O'Brien PE (2012) Does exercise improve weight loss after bariatric surgery? A systematic review. Obes Surg 22: 335 341.

74. Gouni-Berthold I, Brüning JC, Berthold HK (2012) Novel Approaches to the Pharmacotherapy of Obesity. Curr Pharm Des

75. Misra M (2013) Obesity pharmacotherapy: current perspectives and future directions. Curr Cardiol Rev 9: 33-54. 
76. Hainer V, Hainerová IA (2012) Do we need anti-obesity drugs? Diabetes Metab Res Rev 28 Suppl 2: 8-20.

77. O’Brien PE (2010) Bariatric surgery: mechanisms, indications and outcomes. J Gastroenterol Hepatol 25: 1358-1365.

78. Picot J, Jones J, Colquitt JL, Gospodarevskaya E, Loveman E, et al. (2009) The clinical effectiveness and cost-effectiveness of bariatric (weight loss) surgery for obesity: a systematic review and economic evaluation. Health Technol Assess 13: 1-190, 215-357, iii-iv.

79. Colquitt JL, Picot J, Loveman E, Clegg AJ (2009) Surgery for obesity. Cochrane Database Syst Rev : CD003641.

80. Umeda LM, Silva EA, Carneiro G, Arasaki CH, Geloneze B, et al. (2011) Early improvement in glycemic control after bariatric surgery and its relationships with insulin, GLP-1, and glucagon secretion in type 2 diabetic patients. Obes Surg 21: 896-901.

81. Bose M, Teixeira J, Olivan B, Bawa B, Arias S, et al. (2010) Weight loss and incretin responsiveness improve glucose control independently after gastric bypass surgery. J Diabetes 2: 47-55.

82. Ahmed AR, Rickards G, Coniglio D, Xia Y, Johnson J, et al. (2009) Laparoscopic Roux-en-Y gastric bypass and its early effect on blood pressure. Obes Surg 19: 845-849.

83. Sjöström L (2008) Bariatric surgery and reduction in morbidity and mortality: experiences from the SOS study. Int J Obes (Lond) 32 Suppl 7: S93-97.

84. Adams TD, Gress RE, Smith SC, Halverson RC, Simper SC, et al. (2007) Longterm mortality after gastric bypass surgery. N Engl J Med 357: 753-761.

85. Dumon KR, Murayama KM (2011) Bariatric surgery outcomes. Surg Clin North Am 91: 1313-1338, $x$

86. DeMaria EJ, Pate V, Warthen M, Winegar DA (2010) Baseline data from American Society for Metabolic and Bariatric Surgery-designated Bariatric Surgery Centers of Excellence using the Bariatric Outcomes Longitudinal Database. Surg Obes Relat Dis 6: 347-355.

87. Martin M, Beekley A, Kjorstad R, Sebesta J (2010) Socioeconomic disparities in eligibility and access to bariatric surgery: a national population-based analysis. Surg Obes Relat Dis 6: 8-15.

88. (1992) Gastrointestinal surgery for severe obesity: National Institutes of Health Consensus Development Conference Statement. Am J Clin Nutr 55: 615S-619S.

89. Buchwald H; Consensus Conference Panel (2005) Consensus conference statement bariatric surgery for morbid obesity: health implications for patients, health professionals, and third-party payers. Surg Obes Relat Dis 1: 371-381.

90. Scopinaro N, Gianetta E, Civalleri D, Bonalumi U, Bachi V (1979) Biliopancreatic bypass for obesity: II. Initial experience in man. Br J Surg 66: 618620.

91. Hess DS, Hess DW (1998) Biliopancreatic diversion with a duodenal switch. Obes Surg 8: 267-282

92. Forsell P, Hallberg D, Hellers G (1993) A Gastric Band with Adjustable Inner Diameter for Obesity Surgery: Preliminary Studies. Obes Surg 3: 303-306.

93. Ren CJ, Fielding GA (2003) Laparoscopic adjustable gastric banding: surgical technique. J Laparoendosc Adv Surg Tech A 13: 257-263.

94. Marceau P, Hould FS, Simard S, Lebel S, Bourque RA, et al. (1998) Biliopancreatic diversion with duodenal switch. World J Surg 22: 947-954.

95. Regan JP, Inabnet WB, Gagner M, Pomp A (2003) Early experience with twostage laparoscopic Roux-en-Y gastric bypass as an alternative in the supersuper obese patient. Obes Surg 13: 861-864.

96. Brethauer SA, Hammel JP, Schauer PR (2009) Systematic review of sleeve gastrectomy as staging and primary bariatric procedure. Surg Obes Relat Dis 5: 469-475.

97. Fischer L, Hildebrandt C, Bruckner T, Kenngott H, Linke GR, et al. (2012) Excessive weight loss after sleeve gastrectomy: a systematic review. Obes Surg 22: 721-731.

98. Sarkhosh K, Birch DW, Shi X, Gill RS, Karmali S (2012) The impact of sleeve gastrectomy on hypertension: a systematic review. Obes Surg 22: 832-837.

99. Mason EE, Ito C (1996) Gastric bypass in obesity. 1967. Obes Res 4: 316-319.

100. Nguyen NT, Silver M, Robinson M, Needleman B, Hartley G, et al. (2006) Result of a national audit of bariatric surgery performed at academic centers: a 2004 University HealthSystem Consortium Benchmarking Project. Arch Surg 141: 445-449.

101. Wittgrove AC, Clark GW (2000) Laparoscopic gastric bypass, Roux-en-Y- 500 patients: technique and results, with 3-60 month follow-up. Obes Surg 10: 233239.

102. Abdel-Galil E, Sabry AA (2002) Laparoscopic Roux-en-Y gastric bypass-evaluation of three different techniques. Obes Surg 12: 639-642.

103. Bendewald FP, Choi JN, Blythe LS, Selzer DJ, Ditslear JH, et al (2011) Comparison of hand-sewn, linear-stapled, and circular-stapled gastrojejunostomy in laparoscopic Roux-en-Y gastric bypass. Obes Surg 21 1671-1675.

104. Markar SR, Penna M, Venkat-Ramen V, et al. (2012) Influence of circular stapler diameter on postoperative stenosis after laparoscopic gastrojejunal anastomosis in morbid obesity. Surg Obes Relat Dis 8: 230-235.

105. Sjöström L, Narbro K, Sjöström CD, Karason K, Larsson B, et al. (2007) Effects of bariatric surgery on mortality in Swedish obese subjects. $N$ Engl Med 357: 741-752.

106. Pontiroli AE, Morabito A (2011) Long-term prevention of mortality in morbid obesity through bariatric surgery. a systematic review and meta-analysis of trials performed with gastric banding and gastric bypass. Ann Surg 253: 484 487.

107. Sjöström L (2013) Review of the key results from the Swedish Obese Subjects (SOS) trial - a prospective controlled intervention study of bariatric surgery. $J$ Intern Med 273: 219-234.

108. Christou NV, Sampalis JS, Liberman M, Look D, Auger S, et al. (2004) Surgery decreases long-term mortality, morbidity, and health care use in morbidly obese patients. Ann Surg 240: 416-423.

109. Nguyen NT, Paya M, Stevens CM, Mavandadi S, Zainabadi K, et al. (2004) The relationship between hospital volume and outcome in bariatric surgery at academic medical centers. Ann Surg 240: 586-593.

110. Weller WE, Hannan EL (2006) Relationship between provider volume and postoperative complications for bariatric procedures in New York State. J Am Coll Surg 202: 753-761

111. Longitudinal Assessment of Bariatric Surgery (LABS) Consortium, Flum DR, Belle SH, King WC, Wahed AS, et al. (2009) Perioperative safety in the longitudinal assessment of bariatric surgery. N Engl J Med 361: 445-454.

112. Buchwald H, Estok R, Fahrbach K, Banel D, Sledge I (2007) Trends in mortality in bariatric surgery: a systematic review and meta-analysis. Surgery 142: $621-632$.

113. Cadiere GB, Himpens J, Vertruyen M, Favretti F (1999) The world's firs obesity surgery performed by a surgeon at a distance. Obes Surg 9: 206-209.

114. Horgan S, Vanuno D (2001) Robots in laparoscopic surgery. J Laparoendosc Adv Surg Tech A 11: 415-419.

115. Gill RS, Al-Adra DP, Birch D, Hudson M, Shi X, et al. (2011) Robotic-assisted bariatric surgery: a systematic review. Int J Med Robot.
This article was originally published in a special issue, Treatment of Morbid Obesity handled by Editor(s). Dr. Cheryl E. Cammock, Pediatrics Wake Forest Baptist Medical Center, USA 